\title{
Is there a limit for high-pH life?
}

During the past decade, many novel alkaliphilic and alkalitolerant bacterial species have been described, mostly from saline alkaline habitats, such as soda lakes and soda deserts. Most of the papers have been published in this journal, and in many it is claimed that the novel bacteria are capable of growth at $\mathrm{pH}$ as high as 11-12.5. In most of the cases, this 'potential' is also reflected in the name of the organism. Despite this, it is surprising how little effort has been put into obtaining such evidence. Analysis of 19 recent publications (16 in IJSEM, 2 in Extremophiles, 1 in Applied and Environmental Microbiology) from 1999 to 2005 demonstrated that almost none of them contain solid proof of the potential of a novel organism to grow at $\mathrm{pH}$ above 10 (the media not buffered properly, final $\mathrm{pH}$ values not measured or indicated). We consider such a situation alarming and find such papers misleading for the scientific community and general public. When working with alkaliphiles, one should realize that a claim for growth limit as high as $\mathrm{pH} 12$ is very serious, since at such an external $\mathrm{pH}$ the cytoplasmic $\mathrm{pH}$ is bound to be around 10. This would demand adaptation of all intracellular enzymes to highly alkaline conditions - a strategy not yet discovered in bacteria. Up to now, the highest $\mathrm{pH}$ limit for bacterial growth (Bacillus firmus, Nitrosomonas halophila ANs 5), solidly proved in the $\mathrm{pH}$-controlled chemostat, is 11.3-11.4 (Sturr et al., 1994; Sorokin et al., 2001). At higher $\mathrm{pH}$, a collapse of the $\mathrm{pH}$ gradient maintenance was observed.

There are several possible reasons for the described situation. Naturally, it is difficult to find a proper buffering system to maintain stable $\mathrm{pH}$ outside the buffering capacity of the $\mathrm{NaHCO}_{3} / \mathrm{Na}_{2} \mathrm{CO}_{3}$ system the only natural high alkali buffer with maximum capacity between $\mathrm{pH} 9 \cdot 5$ and $10 \cdot 3$. Used at relatively high concentrations,

Published online ahead of print on 15 April 2005 as DOI 10.1099/ijs.0.63737-0. it allows accurate measurement of the ability to grow at $\mathrm{pH} 8 \cdot 5-10 \cdot 4$ for salt-tolerant haloalkaliphiles living in soda lakes, but at $\mathrm{pH}$ above $10 \cdot 4$, even at high concentration, it can not guarantee stable $\mathrm{pH}$ because of the reaction with atmospheric or metabolic $\mathrm{CO}_{2}$. However, in most of the mentioned papers, where carbonate buffer was employed, it was used at very low concentrations (usually $10 \mathrm{~g} \mathrm{l}^{-1}, 0 \cdot 18 \mathrm{M}$ alkalinity), which can not maintain $\mathrm{pH}$ in the hyperalkaline range.

The situation is even more complicated for nonhalophilic organisms isolated from alkaline 'cement' springs, where extremely high $\mathrm{pH}$ is created by the presence of very small amounts (several $\mathrm{mM}$ ) of $\mathrm{Ca}(\mathrm{OH})_{2}$. So it is becoming clear that there is a problem in obtaining realistic $\mathrm{pH}$ limits for growth of newly described organisms. Below we have tried to give some advice on how to obtain realistic data on $\mathrm{pH}$ dependence of organisms from alkaline habitats.

First of all, it is necessary to understand what compounds can be considered ' $\mathrm{pH}$ buffers', since this is a basis for designing proper mineral media for growth and activity tests. The essence is that the buffer resists change in $\mathrm{pH}$ when either acid or alkali is added to it. Therefore the buffer compounds are weak electrolytes, acids or bases, which do not ionize as easily and completely as strong acids and bases such as $\mathrm{HCl}$ and $\mathrm{NaOH}$. Therefore, when one is trying just to adjust an unbuffered medium to a certain $\mathrm{pH}$ with a strong acid or base, the final medium will have no buffering capacity and will have a tendency to rapidly change its $\mathrm{pH}$ during incubation. The $\mathrm{pH}$ at which the buffer compound is half-dissociated is known as its $\mathrm{p} K_{\mathrm{a}}$ value, when the undissociated acid is at equilibrium with its conjugate base. Usually, the buffer has strongest buffering capacity at $\mathrm{pH} \pm 0.5$ of its $\mathrm{p} K_{\mathrm{a}}$. Another parameter determining buffering capacity is, of course, the concentration of the buffer (Beynon \& Easterby, 1996). Also, it is very important that the buffer is not toxic for the organism in question. A useful internet site for understanding how $\mathrm{pH}$ buffers work can be found at http:// www.bi.umist.ac.uk/users/mjfrbn/Buffers/ Bufintro.asp

Our experience with haloalkaliphilic micro-organisms from soda lakes and soils showed that the sodium carbonate buffer system is most appropriate for $\mathrm{pH}$ profiling of growth and activity at a $\mathrm{pH}$ range between $8 \cdot 5$ (pure sodium bicarbonate) and $10 \cdot 4$ (70 \% sodium carbonate/30 \% sodium bicarbonate) at concentrations higher than $0 \cdot 3 \mathrm{M}$ total alkalinity. Still, it was necessary to control final $\mathrm{pH}$ values of the cultures, especially those which produced metabolic acids, such as sulfur-oxidizing bacteria. At lower $\mathrm{pH}$, the best results for growth were obtained with a combination of sodium bicarbonate (20-50 mM), $\mathrm{NaCl}$ (to compensate for salinity) and $0-30 \% \mathrm{CO}_{2}$ in the gas phase at liquid/gas ratio $1: 10$. This allowed maintenance of $\mathrm{pH}$ between $6 \cdot 7$ and $8 \cdot 0$. A combination of $\mathrm{NaHCO}_{3}$ and $\mathrm{KH}_{2} \mathrm{PO}_{4}$ can also be used for this range. However, it was not possible to maintain stable $\mathrm{pH}$ in normal batch cultivation mode, even at $1 \mathrm{M}$ alkalinity, at the level above $\mathrm{pH} 10 \cdot 4$, using any of these buffer systems. As already mentioned above, $\mathrm{pH}$-controlled chemostat cultivation might solve this problem but this technique is not routine and therefore not widely available. In case this option is not available, we recommend measuring a $\mathrm{pH}$ profile for metabolic activity, such as the rate of substrate consumption/oxidation in a rapid test with washed cells. In the case of aerobic organisms, measurements of oxygen consumption rates provide a rapid $\mathrm{pH}$ response. In this case, $\mathrm{pH}$ change is minimal and the carbonate buffer works even at $\mathrm{pH}$ as high as $11 \cdot 5$. Of course the profile for activity would differ from the growth profile, since the activity is only a part of growth. However, the propensity for alkaliphily can be firmly evaluated by this test. According to our experience, the activity profile is usually $1 \mathrm{pH}$ unit broader in both extremes than the growth profile 
with nearly the same maximum. Our usual sets of buffers for activity tests include HEPES-NaCl-NaOH for $\mathrm{pH}$ 6-8 and $\mathrm{NaHCO}_{3} / \mathrm{Na}_{2} \mathrm{CO}_{3}$ for $\mathrm{pH} 8 \cdot 5-11 \cdot 5$. The total sodium content is from $0 \cdot 5$ to $4 \mathrm{M}$ and total potassium is $50 \mathrm{mM}$. Another approach might be to use a very low substrate concentration in growth experiments to minimize the $\mathrm{pH}$ fluctuations.

Organic $\mathrm{pH}$ buffers, which are claimed to be compatible with biological systems, covering the $\mathrm{pH}$ range from $5 \cdot 0$ to $11 \cdot 4$ are available from Sigma-Aldrich (medicine.ucsf.edu/labs/brown/ sigma_buffer_chart.pdf). However, we had a negative experience with the organic buffers in our work with soda lake haloalkaliphiles. For example, such popular organic alkaline buffers as Tris/ $\mathrm{HCl}, \mathrm{CHES}$, CAPSO, CAPS, CABS and glycine- $\mathrm{NaOH}$ usually inhibited cell activity by $50-70 \%$ compared with natural sodium carbonate buffers. One of the possible reasons might be too high a concentration used (50-100 mM). On the other hand, neutral buffers from the sulfonate family, such as MOPS and HEPES, were usually much less inhibitory even for growing cells.

The situation faced by researchers studying nonhalophilic alkaliphiles, such as bacteria living in 'freshwater cement springs' formed during serpentinization of ultrabasic rocks (Pedersen et al., 2004; Tiago et al., 2004), is even more difficult than in the case of haloalkaliphiles, since such organisms can not grow at high osmotic pressure and therefore the growth medium can not be properly buffered. The extremely high $\mathrm{pH}$ in such habitats (up to $12 \cdot 7$ ) is created by the presence of $\mathrm{Ca}(\mathrm{OH})_{2}$ soluble up to $\sim 20 \mathrm{mM}$.

However, as soon as it comes in contact with atmospheric or metabolic $\mathrm{CO}_{2}$, the alkalinity is removed and neutral $\mathrm{CaCO}_{3}$ is precipitated. The main strategy to grow bacteria from the alkaline spring at very high $\mathrm{pH}$ should be based on preventing interference from $\mathrm{CO}_{2}$. For this purpose, sodium carbonate buffer at low concentrations not inhibitory for saltsensitive microbes, natural $\mathrm{Ca}(\mathrm{OH})_{2}$ or CABS ( $\left.\mathrm{p} K_{\mathrm{a}}=10 \cdot 7\right)$ can be used. It is obligatory, however, to monitor the $\mathrm{pH}$ during growth and to evaluate the potential to grow at $\mathrm{pH}$ above 10 by taking into consideration $\mathrm{pH}$ changes in the cultures.

Overall, researchers working with alkaliphilic/alkalitolerant organisms should be more careful when evaluating the $\mathrm{pH}$ dependence of newly described species. Use of proper $\mathrm{pH}$ buffering systems and monitoring $\mathrm{pH}$ change during growth experiments is highly recommended.

\section{Dimitry Yu. Sorokin}

Winogradsky Institute of Microbiology, Russian Academy of Sciences, Moscow 117312, Russia, and Department of Environmental Biotechnology, Delft University of Technology, 2628 BC Delft, The Netherlands

Correspondence: Dimitry Yu. Sorokin (soroc@inmi.host.ru or

D.Y.Sorokin@tnw.tudelft.nl)

Beynon, R. \& Easterby, J. S. (1996). Buffer Solutions: the Basics. Oxford, New York, Tokyo: Oxford University Press.

Pedersen, K., Nilsson, E., Arlinger, J., Hallbeck, L. \& O'Neill, A. (2004). Distribution, diversity and activity of microorganisms in the hyper-alkaline spring waters of Maqarin in Jordan. Extremophiles 8, 151-164.

Sorokin, D. Yu., Tourova, T. P., Schmid, M., Wagner, M., Koops, H.-P., Kuenen, J. G. \& Jetten, M. (2001). Isolation and properties of obligately chemolithoautotrophic and extremely alkali-tolerant ammonia-oxidizing bacteria from Mongolian soda lakes. Arch Microbiol 176, 170-177.

Sturr, M. G., Guffanti, A. A. \& Krulwich, T. A. (1994). Growth and bioenergetics of alkaliphilic Bacillus firmus OF4 in continuous culture at high pH. J Bacteriol 176, 3111-3116.

Tiago, l., Chung, A. P. \& Verissimo, A. (2004).

Bacterial diversity in a nonsaline alkaline environment: heterotrophic aerobic populations. Appl Environ Microbiol 70, 7378-7387. 